\title{
Probabilitas Tegangan Sentuh dan Tegangan Langkah di Lokasi Rencana Gardu Induk 500 kV Antosari
}

\author{
Abdul Latif ${ }^{1}$, Wayan Gede Ariastina ${ }^{2}$, I Nyoman Setiawan ${ }^{3}$
}

\begin{abstract}
Construction of $500 \mathrm{kV}$ high-voltage wires Antosari a follow-up of the plan of PT PLN (Persero), which will increase the supply of electricity to Bali through the system of interconnection of Java - Bali using transmission lines of SUTET $500 \mathrm{kV}$. The research was carried out to analyze the large size grounding comparison with a depth rod conductor to the grounding grid resistance, touch voltage, step voltage and the probability of the onset of touch voltage and step voltage. Calculation of resistance grounding grid using equation IEEE Standard 80-2000 while for the calculation of the touch voltage and step voltage using IEEE Standard 665-1995. Based on the results of research at the site substations for wet soil conditions with extensive grid of $3 \mathrm{~m} \times 3 \mathrm{~m}$ and a depth of $5 \mathrm{~m}$ obtained the grounding grid resistance value of $0,49 \mathrm{ohm}$ and a step voltage value of 125 volt with a probability of $0.72 \%$. As for the dry soil conditions with extensive grid of $3 \mathrm{~m} \times 3 \mathrm{~m}$ and a depth of 5 obtained the grounding grid resistance value of $1.11 \mathrm{ohm}$ and the step voltage value of 281 volt with cumulative probability $0.72 \%$. From the analysis also shows the extensive grid of $3 \mathrm{~m} \times 3 \mathrm{~m}$ and a depth of $0.5 \mathrm{~m}$ obtained values the touch voltage 73 volt for wet soil condition and the 165 volt dry soil conditions with equal cumulative probability is $72 \%$.
\end{abstract}

Intisari- Pembangunan GITET $500 \mathrm{kV}$ Antosari merupakan tindak lanjut dari rencana PT PLN (Persero) yang akan menambah pasokan energi listrik ke Bali melalui sistem interkoneksi Jawa - Bali menggunakan jaringan transmisi SUTET $500 \mathrm{kV}$. Penelitian dilakukan untuk menganalisis perbandingan ukuran luas pentanahan dengan kedalaman batang konduktor terhadap tahanan pentanahan grid, tegangan sentuh, tegangan langkah dan probabilitas timbulnya tegangan sentuh dan tegangan langkah. Perhitungan tahanan pentanahan grid menggunakan persamaan IEEE, Standard 80-2000 sedangkan untuk perhitungan tegangan sentuh dan tegangan langkah menggunakan IEEE, Standard 665-1995. Berdasarkan hasil penelitian di lokasi gardu induk untuk kondisi tanah basah dengan luas grid $3 \mathrm{~m} \times 3 \mathrm{~m}$ dan kedalaman $5 \mathrm{~m}$ didapatkan nilai tahanan pentanahan grid $0,49 \mathrm{ohm}$ dan nilai tegangan langkah 125 volt dengan probabilitas $0,72 \%$. Sedangkan untuk kondisi tanah kering dengan luas grid $3 \mathrm{~m} \times 3 \mathrm{~m}$ dan kedalaman 5 didapatkan nilai tahanan pentanahan grid $1,11 \mathrm{ohm}$ dan nilai tegangan langkah 281 volt dengan probabilitas $0,72 \%$. Dari hasil analisis juga menunjukan dengan luas grid $3 \mathrm{~m} \times 3 \mathrm{~m}$ dan kedalaman $0,5 \mathrm{~m}$ didapatkan nilai tegangan sentuh untuk kondisi tanah basah 73 volt dan pada kondisi tanah kering 165 volt dengan probabilitas yang sama yaitu $72 \%$.

Kata Kunci- Pentanahan Grid, Tegangan Sentuh, Tegangan Langkah, Probabilitas Kumulatif.

\footnotetext{
${ }^{1}$ Mahsiswa, Jurusan Teknik Elektro dan Komputer Fakultas Teknik Universitas Udayana, Jln. Marlboro, Gg X No.14 Denpasar Barat 80119 (Hp: 081338418781; e-mail: latifcalm@gmail.com)

2, 3 Dosen Jurusan Teknik Elektro dan Komputer Fakultas Teknik Universitas Udayana, Jalan Kampus Bukit Jimbaran 80361 INDONESIA
}

Abdul Latif: Probabilitas Tegangan Sentuh dan...

\section{PENDAHULUAN}

Semakin berkembangnya pertindustrian di Indonesia, maka kebutuhan daya listrik yang dibutuhkan semakin meningkat. Untuk memenuhi kebutuhan daya listrik tersebut pada tahun 2016, PT PLN (Persero) merencanakan pembangunan GITET $500 \mathrm{kV}$ Antosari. Pembangunan GITET $500 \mathrm{kV}$ Antosari merupakan tindak lanjut dari rencana PT PLN (Persero) yang akan menambah pasokan energi listrik ke Bali melalui sistem interkoneksi Jawa - Bali menggunakan jaringan transmisi SUTET $500 \mathrm{kV}$, dimulai dari GITET $500 \mathrm{kV}$ Paiton dan akan sampai di GITET $500 \mathrm{kV}$ Antosari.

Gardu Induk merupakan salah satu bagian dari sistem tenaga listrik yang sangat besar mengalami bahaya gangguan yang disebabkan oleh timbulnya arus lebih yang disebabkan oleh petir, sehingga arus ini mengalir kedalam tanah, hal ini terjadi akibat dari isolasi peralatan yang tidak berfungsi dengan baik dan nilai tahanan pentanahan yang cukup besar, maka nilai tahanan pentanahan yang ideal harus memberikan nilai tahanan pembumian mendekati nol atau $\leq 1$ ohm untuk gardu induk bertegangan tinggi [1].

Peranannya yang sangat penting dalam menyalurkan daya listrik dan untuk menjamin keamanan dan keselamatan manusia terhadap bahaya yang sangat tinggi maka pada gardu induk perlu diterapkan suatu sistem pentanahan yang memenuhi persyaratan sistem pengaman.

Dari uraian diatas maka dalam skripsi ini akan mencoba meneliti suatu probabilitas tegangan sentuh dan tegangan langkah pada pentanahan Gardu Induk $500 \mathrm{kV}$ Antosari dengan menggunakan sistem pentanahan grid, dimana sistem pentanahan grid dilakukan dengan cara menanamkan batang konduktor sejajar dengan permukaan tanah pada kedalaman tertentu. Pengukuran akan dilakukan sebanyak lima kali, dengan melakukan pengukuran sebanyak lima kali akan didapatkan nilai rata-rata tahanan jenis tanah dan tahanan pentanahan.

Sistem pentanahan grid sudah banyak digunakan pada gardu induk yang ada di Indonesia dan untuk memperkecil nilai tahanan pentanahan, tegangan sentuh dan tegangan langkah sehingga tegangan yang muncul pada permukaan tanah tidak membahayakan baik dalam kondisi normal ataupun dalam kondisi terjadi gangguan pada tanah. Gardu induk yang akan digunakan sebagai lokasi perencanaan adalah gardu induk $500 \mathrm{kV}$ yang terletak di Antosari yang masih dalam proses konstruksi.

\section{PENTANAHAN}

\section{A. Tahanan Jenis Tanah}

Tahanan jenis tanah merupakan faktor keseimbangan antara tahanan dan kapasitansi. Tahanan jenis tanah disimbolkan dengan $\rho$. Nilai tahanan jenis tanah tergantung dari beberapa faktor yaitu [2]:

$$
\text { p-ISSN:1693 - 2951; e-ISSN: 2503-2372 }
$$


1. Jenis tanah

2. Lapisan tanah

3. Kelembaban tanah

4. Temperatur

Nilai tahanan jenis tanah rata-rata untuk bermacam-macam jenis tanah dapat dilihat pada Tabel 1 [2]:

TABEL 1

TAHANAN BERBAGAI JENIS TANAH

\begin{tabular}{|c|c|}
\hline Jenis Tanah & Tahanan Jenis Tanah ( $\mathbf{\Omega}-\mathbf{m})$ \\
\hline Tanah rawa & 30 \\
\hline Tanah liat dan tanah ladang & 100 \\
\hline Pasir basah & 200 \\
\hline Kerikil basah & 500 \\
\hline Pasir dan kerikil kering & 1000 \\
\hline Tanah berbatu & 3000 \\
\hline
\end{tabular}

Untuk menentukan nilai tahanan jenis tanah dapat dihitung dengan menggunakan Persamaan [3]:

$$
\rho=2 \pi \mathrm{aR}
$$

Dengan,

$\rho=$ Tahanan jenis rata tanah $(\Omega-\mathrm{m})$

$\mathrm{a}=$ Jarak antar batang elektroda yang terdekat (m)

$\mathrm{R}=$ Besar tahanan tanah yang diukur $(\Omega)$

\section{B. Sistem Pentanahan Grid}

Bentuk dari sistem pentanahan mesh dapat dilihat pada Gambar 1:

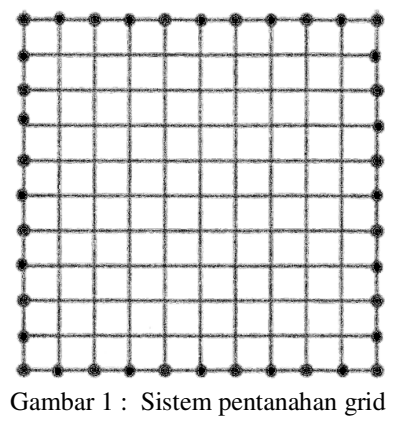

Besarnya nilai tahanan pentanahan dari sistem grid dapat dihitung dengan menggunakan persamaan [1]:

$$
\operatorname{Rg}=\rho\left[\frac{1}{\mathrm{~L}}+\frac{1}{\sqrt{20 \mathrm{~A}}}\left(1+\frac{1}{1+\mathrm{h} \sqrt{20 / \mathrm{A}}}\right)\right]
$$

Dimana,

$\mathrm{Rg}=$ Tahanan pentanahan grid $(\Omega)$

$\rho \quad=$ Tahanan jenis rata tanah $(\Omega-\mathrm{m})$

$\mathrm{L} \quad=$ Jumlah total panjang konduktor batang $\operatorname{rod}(\mathrm{m})$

$\mathrm{h}=$ Kedalaman penanaman konduktor $(\mathrm{m})$

A = Luas area pentanahan grid $\left(\mathrm{m}^{2}\right)$

$$
\mathrm{L}=\mathrm{L}_{\mathrm{c}}+\mathrm{L}_{\mathrm{r}}
$$

Dengan,

Lc $\quad=$ Total panjang konduktor grid $(\mathrm{m})$

$\mathrm{Lr} \quad=$ Total panjang dari batang $\operatorname{rod}(\mathrm{m}$

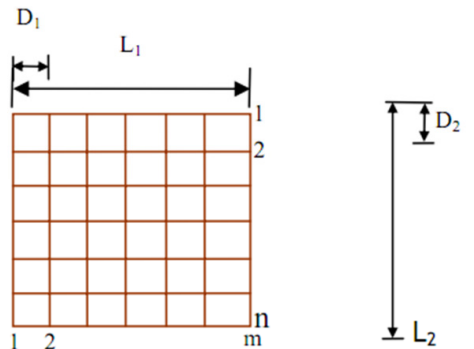

Gambar 2. Sistem pentanahan grid panjang $L_{1}$ dan $L_{2}$

Untuk menentukan panjang konduktor pentanahan grid (Lc) dapat dirumuskan pada Persamaan (4) dengan mengacu pada Gambar 2. [1]:

Dimana,

$$
\mathrm{Lc}=\mathrm{L}_{1} \mathrm{n}+\mathrm{L}_{2} \mathrm{~m}
$$

$$
\begin{aligned}
& D_{1}=\frac{L_{1}}{m-1} \\
& D_{2}=\frac{L_{2}}{n-1}
\end{aligned}
$$

Dengan,

$\mathrm{L}_{1}=$ Panjang konduktor $(\mathrm{m})$

$\mathrm{L}_{2}=$ Lebar konduktor $(\mathrm{m})$

$\mathrm{n}=$ Jumlah konduktor parallel sisi panjang

$\mathrm{m}$ = Jumlah konduktor parallel sisi lebar

$\mathrm{D}_{1}=$ Jarak antar konduktor parallel sisi panjang (m)

$\mathrm{D}_{2}=$ Jarak antar konduktor parallel sisi lebar (m)

\section{Tegangan Sentuh}

Tegangan mesh merupakan salah satu bentuk tegangan sentuh. Tegangan mesh didefinisikan sebagai tegangan peralatan yang diketanahkan terhadap tengah-tengah daerah yang dibentuk konduktor kisi-kisi selama gangguan petir. Tegangan mesh ini menyatakan tegangan tertinggi yang mungkin timbul sebagai tegangan sentuh dan inilah yang diambil sebagai tegangan untuk disain aman [3].

Tegangan sentuh dapat dihitung dengan menggunakan persamaan [4]:

$$
\mathrm{E}_{\mathrm{m}}=\frac{\rho \mathrm{I}_{\mathrm{G}} \mathrm{K}_{\mathrm{m}} \mathrm{K}_{\mathrm{i}}}{\mathrm{L}_{\mathrm{c}}+1,15 \mathrm{~L}_{\mathrm{r}}}
$$

$$
\mathrm{K}_{\mathrm{m}}=\frac{1}{2 \pi}\left[\ln \left(\frac{\mathrm{D}^{2}}{16 \mathrm{hd}}+\frac{(\mathrm{D}+2 \mathrm{~h})^{2}}{8 \mathrm{Dd}}-\frac{\mathrm{h}}{4 \mathrm{~d}}\right)+\frac{\mathrm{K}_{\mathrm{ii}}}{\mathrm{K}_{\mathrm{h}}} \ln \frac{8}{\pi(2 \mathrm{n}-1)}\right]
$$

Dimana Kii = 1 Dengan rod,

$$
\mathrm{K}_{\mathrm{h}}=\sqrt{1+\frac{\mathrm{h}}{\mathrm{h}_{0}}}
$$

$$
\mathrm{Ki}=0,656+0,172 \mathrm{n}
$$


Keterangan :

$\rho \quad=$ Tahanan jenis rata tanah $(\Omega-\mathrm{m})$

IG = Besar arus menuju konduktor grid (A)

$\mathrm{Km}=$ Faktor koreksi dari tegangan grid

$\mathrm{Ki}=$ Faktor koreksi yang terjadi saat peningkatan arus ekstrimitas pada grid

Lc $\quad=$ Total panjang konduktor grid $(\mathrm{m})$

$\mathrm{Lr} \quad=$ Total panjang dari batang rod $(\mathrm{m})$

$\mathrm{Em}=$ Tegangan sentuh yang terjadi pada grid $(\mathrm{V})$

Kii $=$ Faktor koreksi berat efek dari konduktor pada bagian dalam dan pojok grid

$\mathrm{Kh}=$ Faktor koreksi berat pada tekanan dari efek kedalaman grid

$\mathrm{D}=$ Jarak antara konduktor parallel pada kisi-kisi grid (m)

$\mathrm{h} \quad=$ Kedalaman penanaman konduktor $(\mathrm{m})$

h0 = Konstanta kedalaman tanah grid $(1 \mathrm{~m})$

$\mathrm{n} \quad=$ Jumlah konduktor parallel dalam kisi-kisi utama

$\mathrm{n}=\sqrt{\mathrm{n}_{1} \mathrm{X} \mathrm{n}_{2}}$ untuk menghitung nilai $\mathrm{Km}$ dan $\mathrm{Ki}$ dalam menghitung tegangan sentuh

$\mathrm{d}=$ Diameter konduktor kisi-kisi grid (m)

TABEL 2

TEGANGAN SENTUH YANG DIZINKAN

\begin{tabular}{|c|c|}
\hline Lama Gangguan ( t,detik ) & Tegangan Sentuh (Volt) \\
\hline 0,1 & 1980 \\
\hline 0,2 & 1400 \\
\hline 0,3 & 1140 \\
\hline 0,4 & 990 \\
\hline 0,5 & 890 \\
\hline 1,0 & 626 \\
\hline 2,0 & 443 \\
\hline 3,0 & 362 \\
\hline
\end{tabular}

D. Tegangan Langkah

Tegangan langkah adalah perbedaan tegangan yang terdapat diantara kedua kaki bila manusia berjalan di atas tanah sistem pentanahan pada keadaan terjadi gangguan petir [3].

Tegangan langkah dapat dihitung dengan menggunakan Persamaan [4]:

$$
\begin{gathered}
E_{\mathrm{S}}=\frac{\rho \mathrm{I}_{\mathrm{G}} \mathrm{K}_{\mathrm{s}} \mathrm{K}_{\mathrm{i}}}{\mathrm{L}} \\
\mathrm{K}_{\mathrm{s}}=\frac{1}{\pi}\left[\frac{1}{2 \mathrm{~h}}+\frac{1}{\mathrm{D}+\mathrm{h}}+\frac{1}{\mathrm{D}}\left(1-0,5^{\mathrm{n}-2}\right)\right]
\end{gathered}
$$

Keterangan :

Es = Tegangan langkah yang terjadi pada grid ( V )

$\rho=$ Tahanan jenis rata tanah $(\Omega-\mathrm{m})$

$\mathrm{IG}=$ Besar arus menuju konduktor grid (A)

$\mathrm{Ks}=$ Faktor koreksi dari tegangan langkah

$\mathrm{Ki}=$ Faktor koreksi yang terjadi saat peningkatan arus ekstrimitas pada grid

$\mathrm{L}=$ Jumlah total panjang konduktor batang rod (m)

$\mathrm{n}=$ Jumlah konduktor parallel dalam kisi-kisi utama

$\mathrm{n} 1$ dan $\mathrm{n} 2$ yang terbesar digunakan pada $\mathrm{Ks}$ dan $\mathrm{Ki}$ dalam menghitung tegangan langkah

$\mathrm{D}=$ Jarak antara konduktor parallel pada kisi-kisi grid (m)

$\mathrm{h}=$ Kedalaman penanaman konduktor $(\mathrm{m})$

Abdul Latif: Probabilitas Tegangan Sentuh dan...
TABEL 3

TEGANGAN LANGKAH YANG DIZINKAN

\begin{tabular}{|c|c|}
\hline Lama Gangguan ( t, detik ) & Tegangan Sentuh (Volt) \\
\hline 0,1 & 7000 \\
\hline 0,2 & 4950 \\
\hline 0,3 & 4040 \\
\hline 0,4 & 3500 \\
\hline 0,5 & 3140 \\
\hline 1,0 & 2216 \\
\hline 2,0 & 1560 \\
\hline 3,0 & 1280 \\
\hline
\end{tabular}

\section{E. Probabilitas Arus Petir}

Besar tegangan yang timbul pada menara transmisi tergantung pada puncak, kecuraman dan waktu muka gelombang petir. Hubungan antara puncak arus petir dan seringnya terjadi sambaran dapat dilihat pada tabel [5]:

TABEL 4

HUBUNGAN ANTARA ARUS PETIR DAN SERINGNYA TERJADI SAMBARAN

\begin{tabular}{|c|c|}
\hline Arus Puncak Petir (kA) & Probabilitas kejadian (\%) \\
\hline 20 & 36 \\
\hline 40 & 34 \\
\hline 60 & 20 \\
\hline 80 & 8 \\
\hline 100 & 1,2 \\
\hline 160 & 0,5 \\
\hline 200 & 0,3 \\
\hline
\end{tabular}

\section{F. Probabilitas Kumulatif}

Fungsi probabilitas kumulatif digunakan untuk menyatakan jumlah dari seluruh nilai fungsi probabilitas yang lebih kecil atau sama dengan suatu nilai yang ditetapkan. Secara matematis, fungsi probabilitas kumulatif dapat ditulis seperti persamaan [6]:

$$
F(x)=P(X \leq x)=X \leq p(x)
$$

Dengan $\mathrm{F}(\mathrm{x})=\mathrm{P}(\mathrm{X} \leq \mathrm{x})$ menyatakan fungsi probabilitas kumulatif pada titik $\mathrm{X}=\mathrm{x}$ yang merupakan jumlah dari seluruh nilai $X$ sama atau kurang dari $x$. Sedangkan pada probabilitas kumulatif acak kontinu ditentukan dengan fungsi integral, seperti ditunjukan pada persamaan[6]:

$$
F(x)=P(X \leq x)=\int_{-\sim}^{x} f(x) d x
$$

Gambar 3 menunjukkan contoh grafik dari sebuah fungsi probabilitas kumulatif.

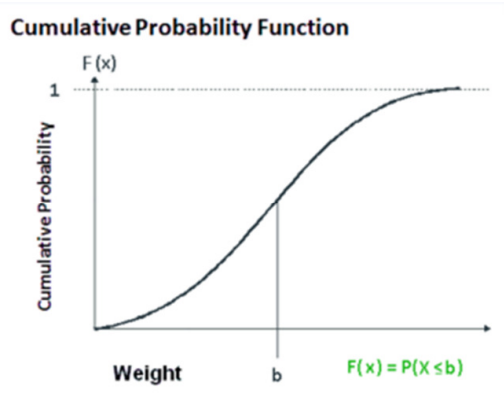

Gambar 3 : Contoh grafik fungsi probabilitas kumulatif p-ISSN:1693 - 2951; e-ISSN: 2503-2372 


\section{METODELOGI PENELITIAN}

Penelitian dilaksanakan di Antosari, Kabupaten Tabanan tempat rencana dibangunnya Gardu Induk $500 \mathrm{kV}$. Waktu pelaksanaan penelitian dilakukan pada bulan Juni 2015 Oktober 2015. Data yang digunakan dalam penyusunan penelitian ini berupa data primer seperti tahanan tanah (R) yang dianalisis di rencana lokasi pembangunan Gardu Induk $500 \mathrm{kV}$. Data sekunder berupa peta gardu induk, spesifikasi gardu dan sambaran petir di Antosari.

Alur ananlisis yang digunakan dalam penelitian ini adalah :

1. Mengumpulkan data tahanan jenis tanah di lokasi Antosari tempat perencanaan lokasi pembangunan Gardu Induk 500 $\mathrm{kV}$.

2. Menganalisis dan menghitung tahanan pentanahan berdasarkan pengamatan data tahanan jenis tanah di rencana lokasi pembangunan Gardu Induk $500 \mathrm{kV}$.

3. Menganalisis dan menghitung tegangan sentuh berdasarkan pengamatan data tahanan jenis tanah di rencana lokasi pembangunan Gardu Induk $500 \mathrm{kV}$.

4. Menganalisis dan menghitung tegangan langkah berdasarkan data tahanan jenis tanah di rencana lokasi pembangunan Gardu Induk $500 \mathrm{kV}$.

5. Membandingkan nilai tahanan pentanahan grid, tegangan sentuh dan tegangan langkah terhadap perbandingan ukuran - ukuran pentanahan grid.

6. Menganalisis probabilitas tegangan sentuh dan tegangan langkah yang mungkin terjadi.

\section{HASIL DAN PEMBAHASAN}

\section{A. Pengukuran Tahanan Tanah di Antosari}

Sesuai dengan hasil pengukuran tahanan pentanahan di Antosari yang dilakukan pada kondisi tanah yang berbeda yaitu tanah basah dan tanah kering. Untuk mendapatkan nilai tahanan pentanahan maka batang konduktor ditanam dengan kedalaman $40 \mathrm{~cm}$ dibawah permukaan tanah. Tahanan jenis tanah didapatkan dengan cara merata-ratakan hasil pengukuran kemudian dilakukan perhitungan.

a) Kondisi tanah basah

$\rho=2 \pi \mathrm{a} \mathrm{R}=2.3,14.20 .0,04=5,02 \Omega-\mathrm{m}$

Dengan menggunakan cara yang sama maka hasil pengukuran tahanan tanah dan perhitungan tahanan jenis tanah dapat dilihat pada tabel berikut :

b) Kondisi tanah kering

$$
\rho=2 \pi \mathrm{a} R=2.3,14.20 .0,09=11,30 \Omega-\mathrm{m}
$$

\section{B. Tahanan Pentanahan}

Dari hasil pengukuran tersebut dapat dilakukan perhitungan untuk mencari nilai tahanan pentanahan grid, dengan mengasumsikan bahwa jenis tanah dilokasi pengukuran adalah homogen.

TABEL 5

HASIL PENGUKURAN TAHANAN TANAH DAN NILAI PERHITUNGAN TAHANAN JENIS TANAH KONDISI BASAH

\begin{tabular}{|c|c|c|c|c|c|c|}
\hline No & Pengukuran & $\begin{array}{c}\text { Waktu } \\
(\text { WITA) }\end{array}$ & $\begin{array}{c}\text { Suhu } \\
\left({ }^{\mathbf{0}} \mathbf{C}\right)\end{array}$ & $\begin{array}{c}\text { Kelembaban } \\
(\mathbf{\%})\end{array}$ & $\begin{array}{c}\mathbf{R} \\
(\mathbf{\Omega})\end{array}$ & $\begin{array}{c}\boldsymbol{\rho} \\
(\mathbf{\Omega}- \\
\mathbf{m})\end{array}$ \\
\hline 1 & Ke-1 & 10.15 & 22 & 85 & 0,04 & 5,02 \\
\hline 2 & Ke-2 & 11.00 & 23 & 75 & 0,04 & 5,02 \\
\hline 3 & Ke-3 & 11.45 & 24 & 74 & 0,04 & 5,02 \\
\hline 4 & Ke-4 & 12.30 & 25 & 69 & 0,04 & 5,02 \\
\hline 5 & Ke-5 & 13.15 & 25 & 69 & 0,04 & 5,02 \\
\hline \multicolumn{7}{|c|}{ Rata - rata } \\
\hline
\end{tabular}

TABEL 6

HASIL PENGUKURAN TAHANAN TANAH DAN NILAI PERHITUNGAN TAHANAN JENIS TANAH KONDISI KERING

\begin{tabular}{|c|c|c|c|c|c|c|}
\hline No & Pengukuran & $\begin{array}{c}\text { Pukul } \\
\text { (WITA) }\end{array}$ & $\begin{array}{c}\text { Suhu } \\
\left({ }^{\mathbf{0}} \mathbf{C}\right)\end{array}$ & $\begin{array}{c}\text { Kelembaban } \\
(\mathbf{\%})\end{array}$ & $\begin{array}{c}\mathbf{R} \\
(\mathbf{\Omega})\end{array}$ & $\begin{array}{c}\boldsymbol{\rho} \\
\mathbf{( \Omega -} \\
\mathbf{m})\end{array}$ \\
\hline 1 & $\mathrm{Ke}-1$ & 09.45 & 24,7 & 51,2 & 0,09 & 11,30 \\
\hline 2 & $\mathrm{Ke}-2$ & 11.15 & 28 & 45,4 & 0,09 & 11,30 \\
\hline 3 & $\mathrm{Ke}-3$ & 12.45 & 30,3 & 52 & 0,09 & 11,30 \\
\hline 4 & $\mathrm{Ke}-4$ & 14.15 & 33,6 & 52,5 & 0,09 & 11,30 \\
\hline 5 & $\mathrm{Ke}-5$ & 15.45 & 30,4 & 58 & 0,09 & 11,30 \\
\hline \multicolumn{7}{|c}{ Rata - rata } \\
\hline
\end{tabular}

\section{Tahanan Pentanahan Grid}

Dalam melakukan perhitungan tahanan pentanahan grid ini digunakan luas area grid mulai dari $1 \mathrm{~m}^{2}$ sampai dengan $9 \mathrm{~m}^{2}$, kedalaman mulai dari $0,5 \mathrm{~m}$ sampai dengan $5 \mathrm{~m}$.

a) Kondisi tanah basah

Luas area grid $1 \mathrm{~m}^{2}$ dan kedalaman $0,5 \mathrm{~m}$ adalah :

$$
\begin{aligned}
\operatorname{Rg} & =\rho\left[\frac{1}{\mathrm{~L}}+\frac{1}{\sqrt{20 \mathrm{~A}}}\left(1+\frac{1}{1+\mathrm{h} \sqrt{20 / \mathrm{A}}}\right)\right] \\
\operatorname{Rg} & =5,02\left[\frac{1}{14}+\frac{1}{\sqrt{20.1}}\left(1+\frac{1}{1+0,5 \sqrt{20 / 1}}\right)\right] \\
& =5,02\left[\frac{1}{14}+\frac{1}{4,472}\left(1+\frac{1}{1+2,236}\right)\right] \\
& =5,02[0,07+0,224(1+0,309)] \\
& =1,83 \Omega
\end{aligned}
$$

b) Kondisi tanah kering

$$
\begin{aligned}
\operatorname{Rg} & =\rho\left[\frac{1}{\mathrm{~L}}+\frac{1}{\sqrt{20 \mathrm{~A}}}\left(1+\frac{1}{1+\mathrm{h} \sqrt{20 / \mathrm{A}}}\right)\right] \\
\operatorname{Rg} & =11,30\left[\frac{1}{14}+\frac{1}{\sqrt{20.1}}\left(1+\frac{1}{1+0,5 \sqrt{20 / 1}}\right)\right] \\
& =11,30\left[\frac{1}{14}+\frac{1}{4,472}\left(1+\frac{1}{1+2,236}\right)\right] \\
& =11,30[0,07+0,224(1+0,309)] \\
& =4,12 \Omega
\end{aligned}
$$


TABEL 7

PERBANDINGAN TAHANAN PENTANAHAN GRID DENGAN LUAS AREA GRID DAN KEDALAMAN TANAH

\begin{tabular}{|c|c|c|c|c|c|}
\hline \multirow{2}{*}{$\begin{array}{c}\text { Kedalaman } \\
\text { tanah }(\mathbf{H}) \\
(\text { meter })\end{array}$} & $\begin{array}{c}\mathrm{A} \\
1 \mathrm{~m}^{2}\end{array}$ & $\begin{array}{c}\mathrm{A} \\
2,25 \\
\mathrm{~m}^{2}\end{array}$ & $\begin{array}{c}\mathrm{A} \\
4 \mathrm{~m}^{2}\end{array}$ & $\begin{array}{c}\mathrm{A} \\
6,25 \\
\mathrm{~m}^{2}\end{array}$ & $\begin{array}{c}\mathrm{A} \\
9 \mathrm{~m}^{2}\end{array}$ \\
\cline { 2 - 6 } & \multicolumn{5}{|c|}{ Tahanan pentanahan grid $(\mathbf{\Omega})$} \\
\hline 0,5 & 1,83 & 1,26 & 0,97 & 0,79 & 0,67 \\
\hline 1 & 1,69 & 0,86 & 0,87 & 0,71 & 0,60 \\
\hline 1,5 & 1,63 & 0,82 & 0,83 & 0,67 & 0,57 \\
\hline 2 & 1,60 & 0,80 & 0,80 & 0,65 & 0,54 \\
\hline 2,5 & 1,57 & 0,79 & 0,79 & 0,63 & 0,53 \\
\hline 3 & 1,56 & 0,78 & 0,77 & 0,62 & 0,52 \\
\hline 3,5 & 1,55 & 0,77 & 0,76 & 0,61 & 0,51 \\
\hline 4 & 1,54 & 0,76 & 0,76 & 0,60 & 0,50 \\
\hline 4,5 & 1,54 & 0,76 & 0,75 & 0,60 & 0,50 \\
\hline 5 & 1,53 & 0,75 & 0,75 & 0,60 & 0,49 \\
\hline
\end{tabular}

TABEL 8

PERBANDINGAN TAHANAN PENTANAHAN GRID DENGAN LUAS AREA GRID DAN KEDALAMAN TANAH

\begin{tabular}{|c|c|c|c|c|c|}
\hline \multirow{2}{*}{$\begin{array}{c}\text { Kedalaman } \\
\text { tanah }(\mathbf{H}) \\
(\text { meter })\end{array}$} & $\begin{array}{c}\mathrm{A} \\
1 \mathrm{~m}^{2}\end{array}$ & $\begin{array}{c}\mathrm{A} \\
2,25 \\
\mathrm{~m}^{2}\end{array}$ & $\begin{array}{c}\mathrm{A} \\
4 \mathrm{~m}^{2}\end{array}$ & $\begin{array}{c}\mathrm{A} \\
6,25 \\
\mathrm{~m}^{2}\end{array}$ & $\begin{array}{c}\mathrm{A} \\
9 \mathrm{~m}^{2}\end{array}$ \\
\cline { 2 - 6 } & \multicolumn{5}{|c|}{ Tahanan pentanahan grid $(\mathbf{\Omega})$} \\
\hline 0,5 & 4,12 & 2,83 & 2,17 & 1,77 & 1,50 \\
\hline 1 & 3,80 & 2,58 & 1,97 & 1,60 & 1,35 \\
\hline 1,5 & 3,66 & 2,46 & 1,87 & 1,51 & 1,27 \\
\hline 2 & 3,59 & 2,40 & 1,81 & 1,46 & 1,23 \\
\hline 2,5 & 3,54 & 2,36 & 1,77 & 1,42 & 1,19 \\
\hline 3 & 3,51 & 2,33 & 1,74 & 1,40 & 1,17 \\
\hline 3,5 & 3,49 & 2,30 & 1,72 & 1,38 & 1,15 \\
\hline 4 & 3,47 & 2,29 & 1,70 & 1,36 & 1,13 \\
\hline 4,5 & 3,45 & 2,27 & 1,69 & 1,35 & 1,12 \\
\hline 5 & 3,44 & 2,26 & 1,68 & 1,34 & 1,11 \\
\hline
\end{tabular}

\section{Arus Grid}

Diasumsikan arus yang mengalir pada gardu induk memliki nilai yang sama pada masing-masing pentanahan. Berdasarkan layout rencana pembangunan Gardu Induk 500 $\mathrm{kV}$ terdapat enam belas pentanahan, sehingga pada saat terjadi sambaran petir yang menghasilkan arus grid dibagi enam belas pentanahan maka didapatkan nilai arus grid pada masing-masing pentanahan gardu induk.

Abdul Latif: Probabilitas Tegangan Sentuh dan...

\section{E. Tegangan Sentuh}

Arus grid $1250 \mathrm{~A}$, luas area pentanahan grid $1 \mathrm{~m}^{2}$ dan kedalaman penanaman batang konduktor $0,5 \mathrm{~m}$.

a) Kondisi tanah basah :

$$
\mathrm{E}_{\mathrm{m}}=\frac{\rho \mathrm{I}_{\mathrm{G}} \mathrm{K}_{\mathrm{m}} \mathrm{K}_{\mathrm{i}}}{\mathrm{L}_{\mathrm{c}}+1,15 \mathrm{~L}_{\mathrm{r}}}=\frac{5,02 \cdot 1250.0,56.1}{6+1,158}=271 \text { Volt }
$$

TABEL 9

PERBANDINGAN TEGANGAN SENTUH DENGAN LUAS AREA GRID DAN KEDALAMAN

\begin{tabular}{|c|c|c|c|c|c|c|}
\hline \multirow{2}{*}{$\begin{array}{c}\text { Kedalaman } \\
\text { tanah (H) } \\
\text { (meter) }\end{array}$} & \multirow{2}{*}{$\begin{array}{c}\mathbf{I}_{\mathbf{G}} \\
\text { (Ampere) }\end{array}$} & $\begin{array}{c}\mathrm{A} \\
1 \mathrm{~m}^{2}\end{array}$ & $\begin{array}{c}\mathrm{A} \\
2,25 \\
\mathrm{~m}^{2}\end{array}$ & $\begin{array}{c}\mathrm{A} \\
4 \mathrm{~m}^{2}\end{array}$ & $\begin{array}{c}\mathrm{A} \\
6,25 \\
\mathrm{~m}^{2}\end{array}$ & $\begin{array}{c}\mathrm{A} \\
9 \mathrm{~m}^{2}\end{array}$ \\
\cline { 3 - 7 } & & \multicolumn{5}{|c|}{ Tegangan sentuh (Volt) } \\
\hline 0,5 & 1250 & 271 & 169 & 120 & 92 & 73 \\
\hline 1 & 1250 & 357 & 229 & 166 & 130 & 106 \\
\hline 1,5 & 1250 & 416 & 270 & 198 & 156 & 128 \\
\hline 2 & 1250 & 459 & 300 & 222 & 175 & 144 \\
\hline 2,5 & 1250 & 494 & 324 & 240 & 190 & 157 \\
\hline 3 & 1250 & 522 & 344 & 456 & 203 & 168 \\
\hline 3,5 & 1250 & 546 & 361 & 269 & 214 & 177 \\
\hline 4 & 1250 & 567 & 375 & 280 & 223 & 185 \\
\hline 4,5 & 1250 & 586 & 388 & 290 & 231 & 192 \\
\hline 5 & 1250 & 603 & 400 & 299 & 239 & 198 \\
\hline
\end{tabular}

b) Kondisi tanah kering

$$
\mathrm{E}_{\mathrm{m}}=\frac{\rho \mathrm{I}_{\mathrm{G}} \mathrm{K}_{\mathrm{m}} \mathrm{K}_{\mathrm{i}}}{\mathrm{L}_{\mathrm{c}}+1,15 \mathrm{~L}_{\mathrm{r}}}=\frac{11,3 \cdot 1250.0,56.1}{6+1,158}=610 \text { Volt }
$$

TABEL 10

PERBANDINGAN TEGANGAN SENTUH DENGAN LUAS AREA GRID DAN KEDALAMAN

\begin{tabular}{|c|c|c|c|c|c|c|}
\hline \multirow{3}{*}{$\begin{array}{c}\text { Kedalaman } \\
\text { tanah (H) } \\
\text { (meter) }\end{array}$} & \multirow{2}{*}{$\begin{array}{c}\mathbf{I}_{\mathbf{G}} \\
\text { (Ampere) }\end{array}$} & $\begin{array}{c}\mathrm{A} \\
1 \mathrm{~m}^{2}\end{array}$ & $\begin{array}{c}\mathrm{A} \\
2,25 \\
\mathrm{~m}^{2}\end{array}$ & $\begin{array}{c}\mathrm{A} \\
4 \mathrm{~m}^{2}\end{array}$ & $\begin{array}{c}\mathrm{A} \\
6,25 \\
\mathrm{~m}^{2}\end{array}$ & $\begin{array}{c}\mathrm{A} \\
9 \mathrm{~m}^{2}\end{array}$ \\
\cline { 3 - 7 } & & \multicolumn{5}{|c|}{ Tegangan sentuh (Volt) } \\
\hline 0,5 & 1250 & 610 & 380 & 270 & 206 & 165 \\
\hline 1 & 1250 & 804 & 515 & 375 & 292 & 238 \\
\hline 1,5 & 1250 & 936 & 607 & 446 & 351 & 288 \\
\hline 2 & 1250 & 1033 & 675 & 499 & 394 & 325 \\
\hline 2,5 & 1250 & 1111 & 729 & 541 & 429 & 354 \\
\hline 3 & 1250 & 1175 & 774 & 576 & 457 & 379 \\
\hline 3,5 & 1250 & 1230 & 812 & 605 & 481 & 399 \\
\hline 4 & 1250 & 1277 & 845 & 631 & 502 & 417 \\
\hline 4,5 & 1250 & 1319 & 874 & 653 & 521 & 433 \\
\hline 5 & 1250 & 1357 & 901 & 673 & 537 & 447 \\
\hline
\end{tabular}

\section{F. Tegangan Langkah}

Arus grid $1250 \mathrm{~A}$, luas area pentanahan grid $1 \mathrm{~m}^{2}$ dan kedalaman penanaman batang konduktor $0,5 \mathrm{~m}$.

a) Kondisi tanah basah

$\mathrm{E}_{\mathrm{s}}=\frac{\rho \mathrm{I}_{\mathrm{G}} \mathrm{K}_{\mathrm{S}} \mathrm{K}_{\mathrm{i}}}{\mathrm{L}}=\frac{5,02.1250 .0,96 \cdot 1,172}{14}=502$ volt

p-ISSN:1693 - 2951; e-ISSN: 2503-2372 
TABEL 11

PERBANDINGAN LUAS AREA GRID DAN KEDALAMAN TANAH

\begin{tabular}{|c|c|c|c|c|c|c|}
\hline \multirow{5}{*}{$\begin{array}{c}\text { Kedalaman } \\
\text { tanah }(\mathbf{H}) \\
(\text { meter })\end{array}$} & \multirow{5}{*}{$\begin{array}{c}\mathbf{I}_{\mathrm{G}} \\
\text { (Ampere) }\end{array}$} & \multicolumn{5}{|c|}{ Luas area grid $(\mathrm{A})$} \\
\hline & & $\mathrm{A}$ & $\mathrm{A}$ & A & $\mathrm{A}$ & $\mathrm{A}$ \\
\hline & & 1 & 2,25 & 4 & 6,25 & 9 \\
\hline & & $\mathrm{m}^{2}$ & $\mathrm{~m}^{2}$ & $\mathrm{~m}^{2}$ & $\mathrm{~m}^{2}$ & $\mathrm{~m}^{2}$ \\
\hline & & \multicolumn{5}{|c|}{ Tegangan langkah (Volt) } \\
\hline 0,5 & 1250 & 502 & 392 & 316 & 261 & 222 \\
\hline 1 & 1250 & 362 & 298 & 245 & 205 & 175 \\
\hline 1,5 & 1250 & 307 & 261 & 217 & 183 & 156 \\
\hline 2 & 1250 & 276 & 241 & 202 & 170 & 146 \\
\hline 2,5 & 1250 & 257 & 228 & 192 & 162 & 139 \\
\hline 3 & 1250 & 243 & 218 & 185 & 157 & 135 \\
\hline 3,5 & 1250 & 233 & 212 & 180 & 153 & 131 \\
\hline 4 & 1250 & 225 & 207 & 176 & 150 & 129 \\
\hline 4,5 & 1250 & 219 & 203 & 173 & 147 & 127 \\
\hline 5 & 1250 & 214 & 199 & 171 & 146 & 125 \\
\hline
\end{tabular}

b) Kondisi tanah kering

$$
\mathrm{E}_{\mathrm{s}}=\frac{\rho \mathrm{I}_{\mathrm{G}} \mathrm{K}_{\mathrm{s}} \mathrm{K}_{\mathrm{i}}}{\mathrm{L}}=\frac{11,3 \cdot 1250.0,96 \cdot 1,172}{14}=1130 \text { volt }
$$

TABEL 12

PERBANDINGAN LUAS AREA GRID DAN KEDALAMAN TANAH

\begin{tabular}{|c|c|c|c|c|c|c|c|}
\hline \multirow{3}{*}{$\begin{array}{c}\text { Kedalaman } \\
\text { tanah (H) } \\
\text { (meter) }\end{array}$} & \multirow{2}{*}{$\begin{array}{c}\mathbf{I}_{\mathbf{G}} \\
\text { (Ampere) }\end{array}$} & $\begin{array}{c}\mathrm{f} \\
1 \mathrm{~m}^{2}\end{array}$ & $\begin{array}{c}\mathrm{A} \\
2,25 \\
\mathrm{~m}^{2}\end{array}$ & $\begin{array}{c}\mathrm{A} \\
4\end{array}$ & $\begin{array}{c}\mathrm{A} \\
6,25 \\
\mathrm{~m}^{2}\end{array}$ & $\begin{array}{c}\mathrm{A} \\
9 \\
\mathrm{~m}^{2}\end{array}$ \\
\cline { 3 - 7 } & & \multicolumn{5}{|c|}{ Tegangan langkah (Volt) } \\
\hline 0,5 & 1250 & 1130 & 882 & 710 & 588 & 499 \\
\hline 1 & 1250 & 816 & 672 & 553 & 462 & 394 \\
\hline 1,5 & 1250 & 690 & 588 & 489 & 411 & 351 \\
\hline 2 & 1250 & 621 & 542 & 455 & 383 & 328 \\
\hline 2,5 & 1250 & 577 & 512 & 433 & 366 & 313 \\
\hline 3 & 1250 & 547 & 492 & 417 & 353 & 303 \\
\hline 3,5 & 1250 & 525 & 477 & 406 & 344 & 295 \\
\hline 4 & 1250 & 507 & 465 & 397 & 337 & 290 \\
\hline 4,5 & 1250 & 494 & 456 & 390 & 332 & 285 \\
\hline 5 & 1250 & 483 & 449 & 385 & 328 & 281 \\
\hline
\end{tabular}

\section{G. Probabilitas Arus Petir Gardu Induk Antosari}

Sambaran petir di Gardu Induk Antosari dari Januari 2014 - Agustus 2015 terdapat 239 sambaran. dengan mengacu pada tabel 4, berikut hubungan antara arus petir dan seringnya terjadi gangguan di Gardu Induk Antosari pada tabel berikut :

TABEL 13

HUBUNGAN ANTARA ARUS PETIR DAN SERINGNYA TERJADI SAMBARAN

\begin{tabular}{|c|c|}
\hline Arus Puncak Petir (kA) & Probabilitas kejadian (\%) \\
\hline 20 & 0,72 \\
\hline 40 & 0,68 \\
\hline 60 & 0,4 \\
\hline 80 & 0,16 \\
\hline 100 & 0,024 \\
\hline 160 & 0,01 \\
\hline 200 & 0,006 \\
\hline
\end{tabular}

\section{H. Probabilitas Tegangan Sentuh dan Tegangan Langkah}

Probabilitas kumulatif timbulnya kejadian tegangan sentuh menggunakan pendekatan seperti tabel 4, tabel 13 dan berdasarkan perhitungan pada sub-bab sebelumnya.

a. Tegangan sentuh kondisi tanah basah

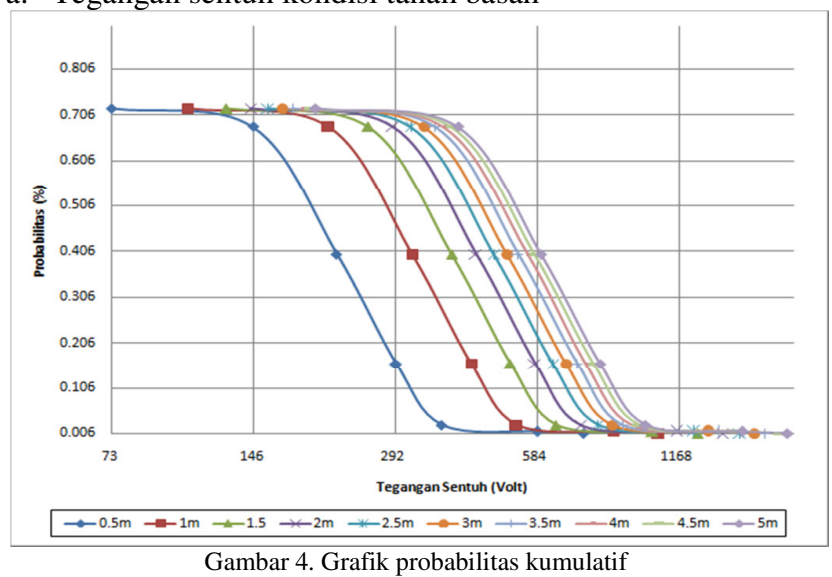

b. Tegangan sentuh kondisi tanah kering

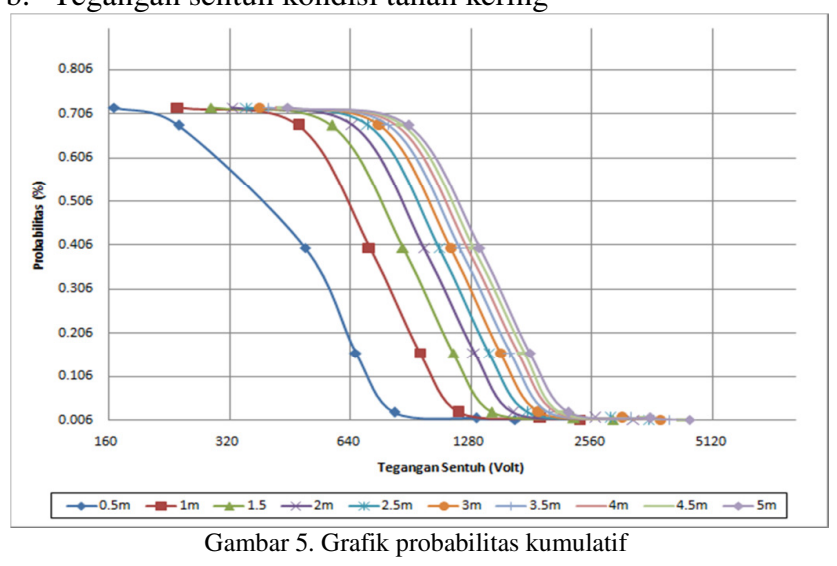

c. Tegangan langkah kondisi tanah basah

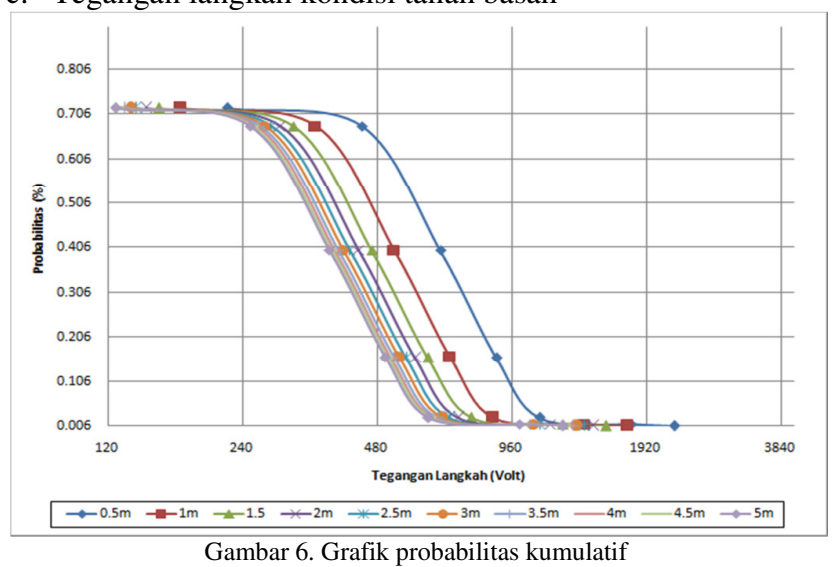


d. Tegangan langkah kondisi tanah kering

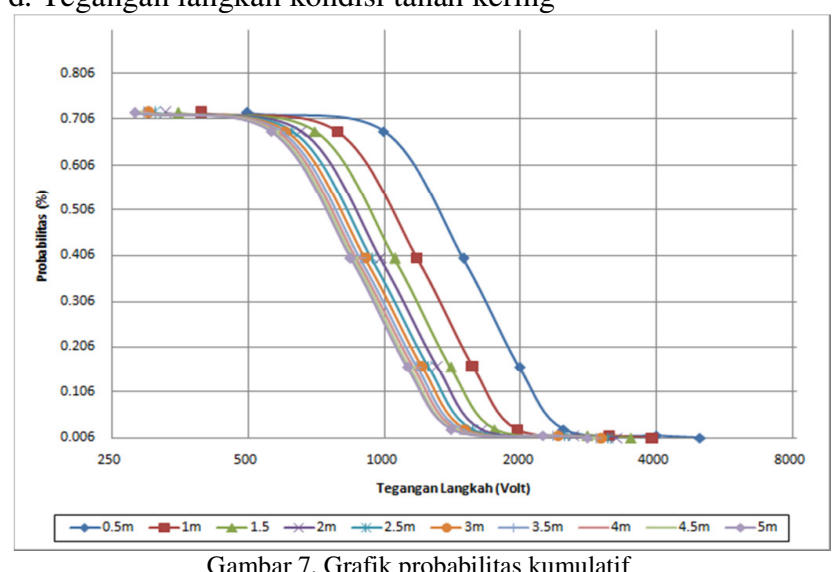

\section{KESIMPULAN}

Berdasarkan hasil analisis dengan luas area pentanahan dari $1 \mathrm{~m}^{2}-9 \mathrm{~m}^{2}$ dengan kedalaman penanaman batang konduktor berkisar $0,5 \mathrm{~m}-5 \mathrm{~m}$ di lokasi rencana Gardu Induk $500 \mathrm{kV}$ Antosari, maka dapat disimpulkan sebagai berikut :

1. Hasil analisis menunjukan bahwa semakin luas area pentanahan grid dan semakin dalam penanaman batang konduktor ( rod ) maka nilai tahanan pentanahan yang didapatkan akan semakin rendah. Dengan luas area pentanahan $9 \mathrm{~m}^{2}$ dan kedalaman penanaman batang konduktor (rod) $5 \mathrm{~m}$ didapatkan nilai tahanan pentanahan grid untuk kondisi tanah basah $0,49 \Omega$ dan kondisi tanah kering $1,11 \Omega$.

2. Dari hasil analisis tegangan sentuh diperoleh bahwa semakin luas area pentanahan grid dan semakin dangkal penanaman batang konduktor (rod) maka tegangan sentuh yang didapatkan akan semakin rendah. Pada kondisi tanah basah dengan luas area pentanahan $9 \mathrm{~m}^{2}$ kedalaman $0,5 \mathrm{~m}$ didapatkan nilai tegangan sentuh 73 volt. Sedangkan saat kondisi tanah kering dengan luas area pentanahan $9 \mathrm{~m}^{2}$ kedalaman 0,5 m didapatakan nilai tegangan sentuh 165 volt dan memiliki nilai probabilitas yang sama yaitu $0,72 \%$.

3. Untuk hasil analisis tegangan langkah didapatkan semakin luas area pentanahan grid dan semakin dalam penanaman batang konduktor (rod) maka tegangan sentuh yang didapatkan akan semakin rendah. Pada kondisi tanah basah dengan luas area pentanahan $9 \mathrm{~m}^{2}$ kedalaman $5 \mathrm{~m}$ didapatakan nilai tegangan langkah 125 volt. Sedangkan saat kondisi tanah kering dengan luas area pentanahan 9 $\mathrm{m}^{2}$ kedalaman $5 \mathrm{~m}$ didapatakan nilai tegangan langkah 281 volt dan memiliki nilai probabilitas yang sama yaitu $0,72 \%$.

\section{REFERENSI}

[1] IEEE Standard 80 - 2000. IEEE Guide for Safety in AC Substation Grounding. New York.

[2] 2000. Peraturan Umum Instalasi LIstrik (PUIL 2000). Jakarta :

[3] Hutauruk, TS. 1999. Pengetanahan Netral Sistem Tenaga Dan Pengetanahan Peralatan. Jakarta : Erlangga.

[4] IEEE Standard 665 - 1995. IEEE Guide for Generating Station Grounding. New York.

[5] Hutauruk, TS. 1991. Gelombang Berjalan dan Proteksi Surja. Jakarta : Erlangga.

[6] Amrita Anak Agung Ngurah, Ariastina Wayan Gede. 2014. Studi Probabilitas Tegangan Sentuh dan Tegangan Langkah dengan Pentanahan Grid Di Lokasi Tower Bali Crossing. Seminar Nasional dan Expo Teknik Elektro 2014. Denpasar : Jurusan Teknik Elektro Fakultas Teknik Universitas Udayana. 